\title{
Implementing the European guidelines for cardiovascular disease prevention in the primary care setting in Cyprus: Lessons learned from a health care services study
} Theodora Zachariadou*1, Henri EJH Stoffers ${ }^{2}$, Costas A Christophi ${ }^{3}$, Anastasios Philalithis ${ }^{4}$ and Christos Lionis ${ }^{5}$

\begin{abstract}
Address: ${ }^{1}$ Nicosia Health Centre, Nicosia, Cyprus, ${ }^{2}$ Department of General Practice, School of Public Health and Primary Care (CAPHRI), Maastricht University, Maastricht, The Netherlands, ${ }^{3}$ Cyprus International Institute for the Environment and Public Health in association with Harvard School of Public Health, Nicosia, Cyprus, ${ }^{4}$ Department of Social Medicine, School of Medicine, University of Crete, Heraklion, Greece and ${ }^{5}$ Department of Social and Family Medicine, School of Medicine, University of Crete, Heraklion, Greece

Email: Theodora Zachariadou* - andthe@cytanet.com.cy; Henri EJH Stoffers - jelle.Stoffers@HAG.unimaas.nl;

Costas A Christophi - coschri@gwu.edu; Anastasios Philalithis - tassos@med.uoc.gr; Christos Lionis - lionis@galinos.med.uoc.gr

* Corresponding author
\end{abstract}

Published: 16 July 2008

BMC Health Services Research 2008, 8:148 doi:10.1186/1472-6963-8-148

This article is available from: http://www.biomedcentral.com/I472-6963/8//48

(c) 2008 Zachariadou et al; licensee BioMed Central Ltd.

This is an Open Access article distributed under the terms of the Creative Commons Attribution License (http://creativecommons.org/licenses/by/2.0), which permits unrestricted use, distribution, and reproduction in any medium, provided the original work is properly cited.

\begin{abstract}
Background: Recent guidelines recommend assessment and treatment of the overall risk for cardiovascular disease (CVD) through management of multiple risk factors in patients at high absolute risk. The aim of our study was to assess the level of cardiovascular risk in patients with known risk factors for CVD by applying the SCORE risk function and to study the implications of European guidelines on the use of treatment and goal attainment for blood pressure (BP) and lipids in the primary care of Cyprus.
\end{abstract}

Methods: Retrospective chart review of IIOI randomly selected patients with type 2 diabetes mellitus (DM2), or hypertension or hyperlipidemia in four primary care health centres. The SCORE risk function for high-risk regions was used to calculate 10-year risk of cardiovascular fatal event. Most recent values of BP and lipids were used to assess goal attainment to international standards. Most updated medications lists were used to compare proportions of current with recommended antihypertensive and lipid-lowering drug (LLD) users according to European guidelines.

Results: Implementation of the SCORE risk model labelled overall $39.7 \%$ (53.6\% of men, 31.3\% of women) of the study population as high risk individuals (CVD, DM2 or SCORE $\geq 5 \%$ ). The SCORE risk chart was not applicable in 563 patients (5I.1\%) due to missing data in the patient records, mostly on smoking habits. The LDL-C goal was achieved in $28.6 \%, 19.5 \%$ and $20.9 \%$ of patients with established CVD, DM2 (no CVD) and SCORE $\geq 5 \%$, respectively. BP targets were achieved in $55.4 \%, 5.6 \%$ and $41.9 \%$ respectively for the above groups. There was under prescription of antihypertensive drugs, LLD and aspirin for all three high risk groups.

Conclusion: This study demonstrated suboptimal control and under-treatment of patients with cardiovascular risk factors in the primary care in Cyprus. Improvement of documentation of clinical information in the medical records as well as GPs training for implementation and adherence to clinical practice guidelines are potential areas for further discussion and research. 


\section{Background}

Cardiovascular disease (CVD) is the major cause of premature death in most European populations [1]; it is an important source of disability and contributes to the escalating costs of health care [2]. In Cyprus, CVD accounts for $41 \%$ of all annual deaths with slight decline in mortality over the last decade [3]. Recent European guidelines stress the importance of integrated cardiovascular risk prediction in planning preventive strategies [1]. The first and most widely used risk prediction tools were developed with data from the Framingham Heart Study [4]. However, several studies have shown that when Framingham risk charts, derived from a northern American population, are applied to European populations they tend to overestimate the risk of an event [5-7]. In 2003, the European guidelines on CVD prevention, recommended the SCORE (Systematic Coronary Risk Evaluation) risk model as a tool in everyday practice [1]. The SCORE system was developed by the SCORE project group [8] who assembled a pool of datasets from 12 European cohort studies in order to calculate separate risk functions for high and low risk regions of Europe. One of the advantages of using the SCORE database for risk assessment is that it can be easily adapted to national conditions, resources and priorities and takes into account the heterogeneity in CVD mortality across European populations [1]. Furthermore it is a relevant tool to general practice where most primary prevention of Coronary Heart Disease (CHD) and management of people with risk factors take place.

Recently the updated version of the European Guidelines on CVD prevention was issued by the Fourth Joint Task Force [9] redefining priorities and objectives on the prevention of CVD.

In Cyprus, a new National Health System (NHS) will be introduced at the end of 2008. Among other tasks, GPs will have a major role in the management of patients with chronic diseases as well as in the development of prevention strategies in order to promote the well being of patients with high risk behaviours and of the population in general. In the context of this reform and prior to the introduction of the NHS a collaborative project was developed with the Clinic of Social and Family Medicine of the University of Crete. One of the goals was to improve the performance of General Practitioners (GPs) in the management of patients with chronic diseases through training and research programs.

The aim of this study which was part of the aforementioned collaboration was to assess the proportion of high risk patients by applying the SCORE risk model in a cohort of patients with known risk factors for CVD in four Primary Care Health Centres in Cyprus. Another objective was to describe the implications of these guidelines for high risk groups with regard to goal attainment of blood pressure and lipids and to compare recommended and current use of antihypertensives and/or lipid lowering drugs.

\section{Methods}

This study was a retrospective cohort analysis of the medical records of selected patients in four Primary Care Health Centres (PCHCs) in Cyprus. The PCHCs enrolled in the study - two urban and two rural - were located in the Nicosia area and were selected using specific selection criteria. Selection was based on the size of the population served by each PCHC, the opening hours of the PCHC, the number of GPs as well as their postgraduate education and years of experience in primary healthcare (PHC) and the number of nurses and administrative staff at each PCHC.

\section{Study participants}

Of the 9504 charts available, 4633 patients with the diagnosis of type 2 diabetes mellitus (DM2), or hypertension or hyperlipidemia were identified. We made a random selection of 1101 patients and reviewed their medical records in order to assess provided care during the year 2002. Patients less than 18 years of age and those who had no visits during the year examined were excluded from the study.

\section{Definitions}

Hypertension was considered present if the diagnosis hypertension was documented in the medical file, or if the patient was on antihypertensive medication or if there were recordings of at least two consecutive measurements of Systolic Blood Pressure (SBP) $\geq 140 \mathrm{mmHg}$ and/or Diastolic Blood Pressure (DBP) $\geq 90 \mathrm{mmHg}$ in the medical records within the year examined [10].

DM2 was considered present if the diagnosis of DM2 was registered in the medical record or by documentation of oral hypoglycemic drugs or combination of oral hypoglycemic drugs and insulin in the medication list or if a fasting plasma glucose (FPG) level $\geq 126 \mathrm{mg} / \mathrm{dl}(7.0 \mathrm{mmol} / \mathrm{l})$ was found [11]. FPG values were provided by the Clinical Biochemistry Department of Nicosia General Hospital.

Cardiovascular disease (CVD) was defined as the presence of coronary heart disease (history of myocardial infarction, ischemic heart disease, angina pectoris or surgical history of either coronary artery bypass grafting or percutaneous transluminal coronary angioplasty) or a major or minor stroke or peripheral artery disease [1].

Hyperlipidemia was considered present if the diagnosis of hyperlipidemia was registered in the medical file, or if patients were on lipid-lowering drugs (LLD) or if there 
was at least one value of Total Cholesterol (TC) $\geq 190 \mathrm{mg} /$ $\mathrm{dl}(5 \mathrm{mmol} / \mathrm{l})$ and/or a value of LDL-Cholesterol $\geq 115$ $\mathrm{mg} / \mathrm{dl}(3 \mathrm{mmol} / \mathrm{l})$ and/or a measurement of Triglycerides (TG) $\geq 150 \mathrm{mg} / \mathrm{dl}$ ( $1.7 \mathrm{mmol} / \mathrm{l})$ documented in their medical records within the year examined [1]. Lipid values were provided by the Clinical Biochemistry Department of Nicosia General Hospital. The biochemistry department uses daily internal controls and participates in three external quality assessment programs.

Medical diagnoses were coded according to the International Classification of Diseases, version 10 (ICD-10) [12] and medications were coded using the fifth level of the Anatomical Therapeutic Chemical system (ATC), version $2000[13]$.

Information regarding smoking status of the patients was not documented in the medical files and was obtained through an interview questionnaire performed by the ten trained nurses of the participating PCHCs. Patients were categorized as 'current smoker', 'former smoker' or 'nonsmoker'.

\section{Patient risk stratification}

The cardiac risk was evaluated through the "SCORE risk function" according to the Third Joint Task Force European guidelines on CVD prevention [1] for high risk regions, as Cyprus, although a Mediterranean country is classified as high risk. The chart comprises a table of the following parameters: sex, smoking status, SBP, TC and age. Risk was estimated by rounding a person's age to the nearest shown on the chart, their TC level to the nearest whole unit and their SBP to the nearest multiple of 20 mmHg [8]. Risk was defined in terms of absolute probability of developing a fatal cardiovascular event within 10 years and the threshold for high risk was defined as $\geq 5 \%$. Patients in whom the algorithm could not be applied due to missing data on several risk factors (i.e. lipids, BP and smoking) were excluded from SCORE calculation and from further analysis on goal attainment. Patients were categorized according to the priorities defined in the European guidelines for CVD prevention $[1,9]$ into the following risk groups: (1) patients with CVD (+/- DM); (2) patients with DM (no CVD); 3) patients at high risk to develop CVD (no CVD, no DM, SCORE $\geq 5 \%$ ); (4) patients with a low risk to develop CVD (no CVD, no DM, SCORE $<5 \%$ ); (5) patients with missing data for risk calculation.

\section{Attainment goals for risk factors}

To assess attainment goals for risk factors, the most recent SBP and DBP, TC, LDL-cholesterol (LDL-C), HDL-cholesterol (HDL-C) and TG values recorded in the medical records were used. These were compared with the recommendations in the European guidelines [1]. For patients with DM2, FBG (fasting blood glucose) and $\mathrm{HbA}_{1 \mathrm{c}}$ (glycated haemoglobin) values were additionally used.

\section{Medical management}

The most updated medication lists were used for analysis of management effectiveness. According to the European guidelines, those patients with a 10 year risk $\geq 5 \%$ of having a fatal CVD event together with SBP $\geq 140 \mathrm{mmHg}$ and/ or TC $\geq 190 \mathrm{mg} / \mathrm{dl}$ ( $5 \mathrm{mmol} / \mathrm{l}$ ) and/or LDL-C $\geq 115 \mathrm{mg} / \mathrm{dl}$ (3 mmol/l) should take antihypertensive and/or LLD and aspirin treatment [1]. For the high risk patients (SCORE risk categories 1,2 , and 3 ) we compared current with recommended treatment patterns for BP and lipids according to the European guidelines. We calculated a delta $(\Delta)$ percentage, which expresses the difference between recommended and observed current drug use. A positive delta percentage indicates that the recommended use exceeds current use.

\section{Statistical analysis}

Descriptive analyses were used to evaluate the characteristics of the total study sample. Continuous variables are presented as means with standard deviations (SD) and categorical variables as percentages. T-test was performed to test for differences on continuous variables between groups. All analyses were conducted using SAS (SAS Institute Inc.) version 9.1. P-values less than 0.05 were considered significant.

\section{Ethics}

Before initiation, the Ethics Committee of Cyprus approved the study [14].

\section{Results \\ Participants' characteristics}

The characteristics of the patients enrolled in the study are shown in Table 1 . Women represented $62.4 \%$ of the overall population $(n=687)$. DM2 was present in $26.8 \%$ of the patients $(\mathrm{n}=295)$. Hypertension and hyperlipidemia were present in 641 (79.5\%) and 313 (38.8\%) non-diabetic patients respectively. Smoking status was known in 364 patients $(33.1 \%)$.

\section{Implementation of SCORE risk chart}

The SCORE risk chart was applicable to 157 patients with multiple risk factors, whereas 563 patients $(51.1 \%)$ were unclassifiable [ $45.6 \%$ of men $(n=189), 54.4 \%$ of women $(\mathrm{n}=374)$ ] due to missing data mostly on smoking habits as shown in Table 1. Of patients with available data for SCORE calculations, approximately $87 \%$ of men and $58 \%$ of women aged 60 were classified as high risk, whereas 101 patients $(18.8 \%)$ from those with available data for SCORE calculation had 10-year risk for fatal CVD event $<5 \%$. 
Table I: Characteristics of the study population $(\mathbf{N}=$ I I 0 I $)$

\begin{tabular}{|c|c|c|c|}
\hline Characteristic & $\begin{array}{l}\text { Men }(n=4 \mid 4) \\
N(\%) \\
\text { Mean } \pm \text { SD }\end{array}$ & $\begin{array}{l}\text { Women }(n=687) \\
\text { N (\%) }\end{array}$ & $\begin{array}{l}\text { Total }(\mathbf{N}=1 \mid l 0 I) \\
\mathbf{N}(\%)\end{array}$ \\
\hline Age (years) & $67 \pm 10.7$ & $67 \pm 10.6$ & $67 \pm 11$ \\
\hline \multicolumn{4}{|l|}{ Age groups (years) } \\
\hline$\leq 64$ & $158(38.2)$ & $276(40.2)$ & $434(39.4)$ \\
\hline$\geq 65$ & $255(61.6)$ & $410(59.7)$ & $665(59.5)$ \\
\hline Missing & $\mathrm{I}(0.2)$ & $I(0.1)$ & $2(0.2)$ \\
\hline \multicolumn{4}{|l|}{ Diagnoses } \\
\hline - DM2 & $134(32.4)$ & $161(23.4)$ & $295(26.8)$ \\
\hline - Hypertension & $307(74.2)$ & $530(77.1)$ & $837(76.0)$ \\
\hline - Hyperlipidemia & $144(34.8)$ & $264(38.4)$ & $408(37.1)$ \\
\hline \multicolumn{4}{|l|}{ SCORE risk category } \\
\hline I. $C V D+/-D M 2 *$ & $68(16.4)$ & $35(5.1)$ & $103(9.4)$ \\
\hline 2. DM2 no CVD & $114(27.5)$ & $146(21.3)$ & $260(23.6)$ \\
\hline 3. High risk** & $40(9.7)$ & $34(4.9)$ & $74(6.7)$ \\
\hline 4. Low risk ${ }^{\dagger}$ & II (2.7) & $90(13.1)$ & $101(9.2)$ \\
\hline 5. Unclassified risk status & $189(45.7)$ & $374(54.4)$ & $563(51.1)$ \\
\hline \multicolumn{4}{|l|}{ Smoking status } \\
\hline - Current smokers & $31(7.5)$ & $10(1.5)$ & $4 \mid(3.7)$ \\
\hline - Former smokers & $64(15.5)$ & II (I.6) & $75(6.8)$ \\
\hline - Non-smokers & $52(12.6)$ & $196(28.5)$ & $248(22.5)$ \\
\hline - Missing smoking status & $267(64.5)$ & $470(68.4)$ & $737(66.9)$ \\
\hline
\end{tabular}

CVD*: definitions see text; DM2: Type 2 Diabetes Mellitus

**Patients with neither CVD nor DM2 but with multiple risk factors resulting in a 10 year risk of $\geq 5 \%$ for developing a fatal CVD event; Patients with TC $\geq 320 \mathrm{mg} / \mathrm{dl}(\geq 8 \mathrm{mmol} / \mathrm{l})$ or $\mathrm{LDL} \geq 240 \mathrm{mg} / \mathrm{dl}(\geq 6 \mathrm{mmlo} / \mathrm{l})$ or $\mathrm{BP} \geq 180 / 110 \mathrm{mmHg}$.

tPatients with neither CVD nor DM2 but with multiple risk factors resulting in a 10 year risk of $<5 \%$ for developing a fatal CVD event.

执 Patients with neither CVD nor DM2 but with missing data on risk factors for score calculation

Goal attainment and patterns of medication use in primary and secondary prevention subgroups

As shown in Table 2, the LDL-C goal $<100 \mathrm{mg} / \mathrm{dl}(2.5$ $\mathrm{mmol} / \mathrm{l}$ ) was achieved in $28.6 \%$ of patients with CVD, $19.5 \%$ of patients with DM2 and $20.9 \%$ of those with multiple risk factors for CVD. When we applied the more stringent recommendations of the 2007 European guidelines [9], only $5 \%$ of the patients with CVD and $8 \%$ of DM2 patients had LDL-C $<80 \mathrm{mg} / \mathrm{dl}$.

BP targets were achieved in 55.4\%, 5.6\% and $41.9 \%$ respectively. Patterns of the gap between recommended and current drug use are shown in Table 3. All delta percentages were positive for the three groups, indicating under prescription of medication. The smallest gap was observed for antihypertensive medication in patients with CVD $(\Delta=3.6 \%)$, the largest gap was observed among non-diabetic high-risk patients for aspirin use $(\Delta=89.2$ $\%)$.

\section{Discussion Main findings}

This was the first study in Cyprus on cardiovascular risk stratification by means of the SCORE system according to the European guidelines. The implementation of this risk model in a selected cohort of primary care patients with established risk factors for CVD has labelled a substantial proportion as high risk individuals (overall 39.7\%). Almost $90 \%$ of men aged 55 and $57.8 \%$ of women aged 60 were classified as high risk. In a similar study by Getz et al [15], 91.4\% of men aged 55 and $57.3 \%$ of women at age 60 were classified as high risk according to SCORE chart, findings that are in accordance with those of our study.

In addition, this study demonstrates a gap between recommended and current drug use for the high risk population. Two studies from Norway $[16,17]$ found that $42 \%$ and $52 \%$ of men aged $45-64$ respectively would be candidates for antihypertensive or LLD treatment, whereas according to another study [18], 29\% of dyslipidemic patients should receive LLD. In our study, the gap between recommended and current antihypertensive use was 
Table 2: Goal attainment of blood pressure and lipids in high-risk patients according to the European guidelines with respective mean values.

\begin{tabular}{|c|c|c|}
\hline Parameters & Mean \pm SD & Number of patients (\%) \\
\hline \multicolumn{3}{|c|}{ SCORE RISK CATEGORY I (CVD; $n=103)$} \\
\hline $\mathrm{TC}(\mathrm{mg} / \mathrm{dl}), \mathrm{n}=42$ & $207 \pm 32.6$ & \\
\hline$\cdot<175 \mathrm{mg} / \mathrm{dl}(4.5 \mathrm{mmol} / \mathrm{l})$ & & $7(16.7)$ \\
\hline$\bullet \geq 175 \mathrm{mg} / \mathrm{dl}$ & & $35(83.3)$ \\
\hline - missing (\% of total $\mathrm{N})$ & & $61(59.2)$ \\
\hline LDL-C (mg/dl), $\mathrm{n}=2 \mathrm{I}$ & $121 \pm 36.9$ & \\
\hline$\cdot<100 \mathrm{mg} / \mathrm{dl}(2.5 \mathrm{mmol} / \mathrm{l})$ & & $6(28.6)$ \\
\hline$\cdot \geq 100 \mathrm{mg} / \mathrm{dl}$ & & $15(7 \mid .4)$ \\
\hline - missing (\% of total $\mathrm{N})$ & & $82(79.6)$ \\
\hline $\mathrm{BP}(\mathrm{mmHg}), \mathrm{n}=83$ & $132 \pm 15.2(\mathrm{SBP})$ & $80 \pm 6.6$ (DBP) \\
\hline$\cdot<140 / 90 \mathrm{mmHg}$ & & $46(55.4)$ \\
\hline$\cdot \geq 140 / 90 \mathrm{mmHg}$ & & $37(44.6)$ \\
\hline - missing (\% of total $\mathrm{N})$ & & $20(19.4)$ \\
\hline \multicolumn{3}{|c|}{ SCORE RISK CATEGORY 2 (DM2, no CVD; $n=260)$} \\
\hline $\mathrm{TC}(\mathrm{mg} / \mathrm{dl}), \mathrm{n}=136$ & $216 \pm 43.2$ & \\
\hline - $<175 \mathrm{mg} / \mathrm{dl}(4.5 \mathrm{mmol} / \mathrm{l})$ & & $23(16.9)$ \\
\hline$\cdot \geq 175 \mathrm{mg} / \mathrm{dl}$ & & $113(83.1)$ \\
\hline$\cdot$ missing (\% of total $\mathrm{N})$ & & $124(47.7)$ \\
\hline LDL-C (mg/dl), $n=77$ & $127 \pm 36.0$ & \\
\hline$\bullet<100 \mathrm{mg} / \mathrm{dl}(2.5 \mathrm{mmol} / \mathrm{l})$ & & $15(19.5)$ \\
\hline$\cdot \geq 100 \mathrm{mg} / \mathrm{dl}$ & & $62(80.5)$ \\
\hline - missing (\% of total $N$ ) & & $183(70.4)$ \\
\hline $\mathrm{BP}(\mathrm{mmHg}), \mathrm{n}=213$ & $138 \pm 15.8(\mathrm{SBP})$ & $82 \pm 7.4$ (DBP) \\
\hline$\cdot<130 / 80 \mathrm{mmHg}$ & & $12(5.6)$ \\
\hline$\cdot \geq 130 / 80 \mathrm{mmHg}$ & & $201(94.4)$ \\
\hline - missing (\% of total $\mathrm{N})$ & & $47(18.1)$ \\
\hline $\mathrm{HbA}_{\mathrm{Ic}}(\%), \mathrm{n}=3 \mathrm{I}$ & $7.2 \pm 1.3$ & \\
\hline$\cdot<7 \%$ & & $12(38.7)$ \\
\hline$\cdot \geq 7 \%$ & & $19(61.3)$ \\
\hline - missing (\% of total $\mathrm{N})$ & & $229(88.1)$ \\
\hline \multicolumn{3}{|c|}{ SCORE RISK CATEGORY $3($ SCORE $\geq 5 \% ; n=74)$} \\
\hline $\mathrm{TC}(\mathrm{mg} / \mathrm{dl}), \mathrm{n}=7 \mathrm{l}$ & $241 \pm 76.3$ & \\
\hline$\cdot<175 \mathrm{mg} / \mathrm{dl}(4.5 \mathrm{mmol} / \mathrm{l})$ & & $8(11.3)$ \\
\hline$\cdot \geq 175 \mathrm{mg} / \mathrm{dl}$ & & $63(88.7)$ \\
\hline - missing (\% of total $\mathrm{N})$ & & $5(6.8)$ \\
\hline LDL-C (mg/dl), $n=43$ & $144 \pm 49.6$ & \\
\hline$\cdot<100 \mathrm{mg} / \mathrm{dl}(2.5 \mathrm{mmol} / \mathrm{l})$ & & $9(20.9)$ \\
\hline$\cdot \geq 100 \mathrm{mg} / \mathrm{dl}$ & & $34(79.1)$ \\
\hline - missing (\% of total $N$ ) & & $33(43.5)$ \\
\hline $\mathrm{BP}(\mathrm{mmHg}), \mathrm{n}=74$ & $142 \pm 20.0(\mathrm{SBP})$ & $82 \pm 9.1$ (DBP) \\
\hline$-<140 / 90 \mathrm{mmHg}$ & & $31(4 \mid .9)$ \\
\hline$\cdot \geq 140 / 90 \mathrm{mmHg}$ & & $43(58.1)$ \\
\hline - missing (\% of total $N$ ) & & $0(0)$ \\
\hline
\end{tabular}

TC: Total Cholesterol; LDL-C: Low Density Lipoprotein Cholesterol: BP: Blood Pressure, SBP: Systolic Blood Pressure, DBP: Diastolic Blood Pressure, $\mathrm{HbA}_{\mathrm{Ic}}$ : Glycated hemoglobin

larger in the diabetic group of patients (13.1\%). The fact that only $42 \%$ of patients with CVD were taking LLD and even less (29\%) achieved recommended LDL-C is a matter of concern. In a study from Spain [19], 65\% of patients with CHD were on LLD and 31\% of those achieved LDL$\mathrm{C}$ target whereas in a retrospective study by Straka et al [20], 71\% of patients with CHD were on LLD and 35\% of those had LDL $<100 \mathrm{mg} / \mathrm{dl}$. Harz et al [21] showed that
$50 \%$ of patients with CHD were on LLD and one in three reached lipid goal. According to the results of EUROASPIRE [22] I and II, 54\% of patients with established CHD had BP off target ( $\geq 140 / 90 \mathrm{mmHg}$ ) as compared to $44.6 \%$ of our study patients of the similar group.

Regarding the diabetic population of the study $19.5 \%$ achieved their LDL-C goal. In other studies [23-25] these 
Table 3: Proportion of high risk patients on treatment as recommended by the European guidelinest. Proportion of low risk patients and of unclassified patients on treatment.

\begin{tabular}{|c|c|c|c|c|c|c|c|c|}
\hline \multirow{2}{*}{$\begin{array}{l}\text { SCORE risk category } \\
\text { Treatment }\end{array}$} & \multicolumn{2}{|c|}{ (I) CVD (n=I03) } & \multicolumn{2}{|c|}{ (2) DM2 $(n=260)$} & \multicolumn{2}{|c|}{ (3) SCORE $\geq 5 \%(n=74)$} & \multirow{2}{*}{$\begin{array}{l}\text { (4) SCORE }<5 \% \\
(n=I 0 I) \\
N(\%)\end{array}$} & \multirow{2}{*}{$\begin{array}{l}\text { (5) } \\
\text { Unclassified(n=563) } \\
N(\%)\end{array}$} \\
\hline & $N(\%)$ & $\Delta(\%)$ & $N(\%)$ & $\Delta(\%)$ & $N(\%)$ & $\Delta(\%)$ & & \\
\hline $\begin{array}{l}\text { ANTIHYPERTENSIV } \\
\text { ES }\end{array}$ & & 3.6 & & I3.1 & & 6.7 & & \\
\hline - Current & $34(4 \mid .0)$ & & $86(40.4)$ & & $38(51.4)$ & & 7I (70.3) & 382 (67.9) \\
\hline - Recommended & $37(44.6)$ & & $114(53.5)$ & & $43(58.1))$ & & - & - \\
\hline LLD & & 30.2 & & 38.9 & & 47.9 & & \\
\hline - Current & $18(4 \mid .9)$ & & $50(36.8)$ & & $27(38.0)$ & & $46(45.5)$ & $173(30.7)$ \\
\hline - Recommended & $31(72.1)$ & & $103(75.7)$ & & $61(85.9)$ & & - & - \\
\hline ASPIRIN & & 53.4 & & 87.7 & & 89.2 & & \\
\hline - Current & $48(46.6)$ & & $32(12.3)$ & & $8(10.8)$ & & $25(24.8)$ & $13(2.3)$ \\
\hline - Recommended & $103(100)$ & & $260(100)$ & & $74(100)$ & & - & - \\
\hline \multicolumn{9}{|c|}{$\begin{array}{l}\text { SCORE risk categories: } \\
\text { (1): Patients with CVD +/- DM2 } \\
\text { (2): Patients with DM2 (no CVD) } \\
\text { (3): Patients with neither CVD nor DM2 but with multiple risk factors resulting in a } 10 \text { year risk of } \geq 5 \% \text { for developing a fatal CVD event; Patients } \\
\text { with TC } \geq 320 \mathrm{mg} / \mathrm{dl}(\geq 8 \mathrm{mmol} / \mathrm{l} \text { ) or } \mathrm{LDL} \geq 240 \mathrm{mg} / 7 \mathrm{dl}(\geq 6 \mathrm{mmlo} / \mathrm{l} \text { ) or } \mathrm{BP} \geq 180 / \mathrm{l} 10 \mathrm{mmHg} \text {. } \\
\text { (4): Patients with neither CVD nor DM2 but with multiple risk factors resulting in a } 10 \text { year risk of }<5 \% \text { for developing a fatal CVD event. } \\
\text { (5): Patients with neither CVD nor DM2 but with missing data on risk factors for score calculation } \\
+ \text { tValues are for those patients with available data }\end{array}$} \\
\hline
\end{tabular}

percentages ranged from $16.5 \%$ to $53 \%$, whereas in a Greek study [26] 17.5\% of diabetic patients achieved LDL$\mathrm{C}<100 \mathrm{mg} / \mathrm{dl}$. BP control was particularly low among patients with DM2 (7.5\%) as compared to other studies [23,25,27-29], with percentages ranging between $10.3 \%$ and 35\%. Women with DM2 had worse mean FBG (160 vs $140 \mathrm{mg} / \mathrm{dl}, \mathrm{p}=0.044$ ) as compared to diabetic men, a findings also supported by an Italian study [25].

\section{Limitations}

Several limitations of our study should be noted. This study examined a selected population of patients with already known risk factors for CVD (hypertension, hyperlipidemia, DM2) and was not performed in healthy individuals. Thus, our findings are restricted to this clinical segment of the population. Also, the study was performed in only four PCHCs from the total of fifteen in Nicosia area and in only one area of the island. Results must thus, be interpreted with caution and cannot be generalised for the entire population of the island.

Furthermore, many of the patients were already receiving antihypertensive or LLD treatment which could have modified their risk profile at the time of their risk assessment. In addition, the SCORE risk chart could not be calculated in over $50 \%$ of the participants due to underreporting of clinical information in the medical files. As a result, the 10-year risk for a fatal cardiovascular event is unknown for more than half of the studied patients and therefore we can not draw conclusion for the remaining population of the study.

Implications of the study to national health care policy

There are some important messages derived from this study that should convey to health policy makers who are responsible for the design and implementation of the new NHS in Cyprus. The fact that GPs underreport clinical information (smoking behaviour, lipid values and BP) is indeed a matter of concern. It should be stressed out that a major step in improving the management of CVD risk factors is to accurately report them and treat them. However, there have not been any studies so far in the PHC setting of Cyprus to assess the level of documentation of clinical information by the GPs. We can either assume that GPs do perform blood tests, measure BP and ask about the smoking habits of their patients but they do not document this information in the medical files or that they simply do not perform them. These however, are only assumptions and further studies are needed in order to reach safe conclusion. Also, as shown from our results, GPs do not follow clinical practice guidelines in their everyday practice for the management of patients with common chronic conditions. This was indicated from the under-treatment of high risk patients as well as from gaps in goal attainment. Potential barriers could be administrative, educational and time pressures. These issues could be addressed through introduction of organisational systems to support the management of patients with chronic dis- 
eases (i.e. registries, computerised recall and reminder systems) as well as effective charting systems (e.g. flow sheets) to improve quality assurance and documentation [29].

Furthermore, our study was performed before the publication of the recent European guidelines $[1,9]$ and therefore GPs were unaware of the recommendations stated in the guidelines. However, our intention was to have an initial evaluation of the care delivered in the PHC setting of Cyprus in order to identify failures and stimulate for actions before the introduction of the new NHS. This study served as the first part of a quality project that was followed by the implementation of a multifaceted intervention in DM2 patients.

Finally, the fact that Cyprus is included in the high risk regions for CVD and whether these guidelines overestimate risk in the general population are matters that should raise discussion. So far, there are no national guidelines for CVD prevention and only recently the Cyprus College of Cardiology adapted the Greek version of the European guidelines. Until epidemiological studies are performed addressing the above mentioned issues, including the assessment of the risk level of the population at risk for CVD, current guidelines could and should serve as a tool to GPs for prioritising patients in order to address the role of lifestyle changes, the management of cardiovascular risk factors and the use of other prophylactic drug therapies in the prevention of clinical CVD.

\section{Conclusion}

Implementation of the European guidelines in patients with risk factors for CVD in the Primary Care in Cyprus has classified a substantial proportion at high risk for fatal cardiovascular event and revealed suboptimal quality of care with regard to risk factor registration, medical treatment and achievement of treatment targets. The study results could act as a stimulus to improve Cypriot primary care for cardiovascular disease.

\section{Authors' contributions}

CL conceived the idea of the study, participated in the design of the study and contributed to the draft and final version of the manuscript. $\mathrm{TZ}$ designed and coordinated the study and drafted the manuscript. HEJHS participated in the design of the study and contributed to the draft and the final version of the manuscript. CAC performed the statistical analysis. AP contributed to the final version of the manuscript. All authors read and approved the final manuscript.

\section{Acknowledgements}

The authors would like to thank the officers of the Ministry of Health of Cyprus who supported this study as well as the general practitioners, the nurses and administrative staff of the participating primary care health cen- tres. This study was entirely financially supported by the Ministry of Health of Cyprus.

\section{References}

I. De Backer G, Ambrosioni E, Borch-Johnsen K, Brotons C, Cifkova R, Dallongeville J, Ebrahim S, Faergeman O, Graham I, Mancia G, Manger Cats V, Orth-Gomér K, Pyörälä K, Rodicio JL, Sans S, Sansoy V, Sechtem U, Silber S, Thomsen T, Wood D: Third Joint Task Force of European and Other Societies on Cardiovascular Disease Prevention in Clinical Practice. European guidelines on cardiovascular disease prevention in clinical practice. Eur Heart J 2003, 24:1601-1610.

2. Graham IM: Guidelines on cardiovascular disease prevention in clinical practice: the European perspective. Curr Opin Cardiol 2005, 20:430-439.

3. Health and Hospital Statistics: Statistical Service of Cyprus 2004, I:284-285.

4. Anderson KM, Odell PM, Wilson PWF, Kannel WB: Cardiovascular risk profiles. Am Heart J 1990, I 2 I:293-298.

5. Marrugat J, D'Agostino R, Sullivan L, Elosua R, Wilson P, Ordovas J, Solanas P, Cordón F, Ramos R, Sala J, Masiá R, Kannel WB: An adaptation of the Framingham coronary heart disease risk function to European Mediterranean areas. J Epidemiol Community Health 2003, 57:634-638.

6. Hense HW, Schulte H, Lowel H, Assmann G, Keil U: Framingham risk function overestimates risk of coronary heart disease in men and women from Germany-results from the MONICA Augsburg and the PROCAM cohorts. Eur Heart J 2003, 24:937-945.

7. Menotti A, Puddu PE, Lanti M: Comparison of the Framingham risk function based coronary chart with risk function from an Italian population study. Eur Heart J 2000, 2 I :365-370.

8. Conroy RM, Pyorala K, Fitzgerald AP, Sans S, Menotti A, De Backer $G$, De Bacquer $D$, Ducimetière $P$, Jousilahti $P$, Keil U, Njølstad I, Oganov RG, Thomsen T, Tunstall-Pedoe H, Tverdal A, Wedel H, Whincup P, Wilhelmsen L, Graham IM, on behalf of the SCORE project group: Estimation of ten year risk of fatal cardiovascular disease in Europe: the SCORE project. Eur Heart J 2003, 24:987-1003.

9. Graham I, Atar D, Borch-Johnsen K, Boysen G, Burell G, Cifkova R, Dallongeville J, De Backer G, Ebrahim S, Gjelsvik B, Herrmann-Lingen C, Hoes A, Humphries S, Knapton M, Perk J, Priori S, Pyörälä K, Reiner Z, Ruilope L, Sans-Menendez S, Scholte Op Reimer W, Weissberg P, Wood D, Yarnell J, Zamorano JL: European guidelines on cardiovascular disease prevention in clinical practice. Fourth Joint Task Force of the European Society of Cardiology and other Societies on Cardiovascular Disease Prevention in Clinical Practice. Eur J Cardiovasc Prev Rehabil 2007, I4(S2):SI-SI I3.

10. Chobanian A, Bakris G, Black H, Cushman W, Green L, Izzo J, Jones D, Materson B, Oparil S, Wright J, Roccella E, the National High Blood Pressure Education Program Coordinating Committee: The Seventh Report of the Joint National Committee on Prevention, Detection, Evaluation and Treatment of High Blood Pressure. JAMA 2003, 289:2560-2572.

II. Gabir MM, Hanson RL, Dabelea D, Imperatore G, Roumain J, Bennett $\mathrm{PH}$, Knowler WC: The 1997 American Diabetes Association and 1999 World Health Organisation Criteria for Hyperglycaemia in the Diagnosis and Prediction of Diabetes. Diabetes Care 2000, 23: I I08-III2.

12. International Statistical Classification of Diseases and Related Health Problems. In IOth revision Volume I. WHO: Geneva; 1992.

13. WHO Collaborating Centre for Drug Statistics Methodology: ATC index 2000 with DDDs. [http://www.whocc.no/atcddd]. Accessed 24 April 2007

14. Cyprus National Bioethics Committee: [http://www.bioethics.gov.cy/ Law/cnbc/cnbc.nsf/DMLindex en/DMLindex en?OpenDocument]. Accessed 18/I2/200I.

15. Getz L, Sigurdsson JA, Hetlevik I, Kirkengen AL, Romundstad S, Holmen J: Estimating the high risk group for cardiovascular disease in the Norwegian HUNT 2 population according to the 2003 European guidelines: modeling study. BMJ 2005, 33 I :55 I.

16. Harz I, Njølstad I, Eggen AE: Does implementation of the European guidelines based on the SCORE model double the 
number of Norwegian adults who need cardiovascular drugs for primary prevention? The Trømso study 200I. Eur Heart J 2005, 26:2673-2680.

17. Brekke M, Rekdal M, Straand J: Which population groups should be targeted for cardiovascular prevention? A modeling study based on the Norwegian Hordaland Health Study (HUSK). Scand J Prim Health Care 2007, 25: I05- III.

18. Fornasini M, Brotons C, Sellarès J, Martinez M, Galán ML, Sáenz I, da Pena JM: Consequences of using different methods to assess cardiovascular risk in primary care. Fam Pract 2006, 23:28-33.

19. Turon JM, Librero J, Diaz GJ, Garcia JJ, Beltral C, Abal F, on behalf of the Redimer study group (SEMFYC): Auditing secondary prevention of ischemic heart disease in rural areas of Spain: an opportunity for improvement. Eur J Gen Pract 2006, I 2: I 56- I62.

20. Straka RJ, Taheri R, Cooper SL, Tan AWH, Smith JC: Assessment of hypercholesterolemia control in a managed care organization. Pharmacotherapy 200I, 21:818-827.

21. Hartz I, Eggen AE, Grimsgaard S, Skjold F, Njølstad I: Whom are we treating with lipid-lowering drugs? Are we following the guidelines? Evidence from a population based study: the Trømso study 200 I. Eur J Clin Pharmacol 2004, 60:643-649.

22. Kotseva K, Wood D, De Backer G, De Bacquer D, Pyörälä K, Keil U, Sans S: Clinical reality of coronary prevention guidelines: a comparison of EUROASPIRE I and II in nine countries. Lancet 200I, 357:995-I00I.

23. Johnson ML, Pietz K, Battleman DS, Beyth RJ: Therapeutic goal attainment in patients with hypertension and dyslipidemia. Med Care 2006, 44:39-46.

24. Pearson TA, Laurora I, Chu $\mathrm{H}$, Kafonek S: The lipid treatment assessment project (L-TAP): a multicenter survey to evaluate the percentages of dyslipidemic patients receiving lipidlowering therapy and achieving low-density lipoprotein cholesterol goals. Arch Intern Med 2000, 160:459-467.

25. Vaccaro O, Boemi M, Cavalot F, De Feo P, Miccoli R, Patti L, Rivellese AA, Trovati M, Ardigò D, Zavaroni I: The clinical reality of guidelines for primary prevention of cardiovascular disease in type 2 diabetes in Italy. Atherosclerosis 2008, 198(2):396-402.

26. Gikas A, Sotiropoulos A, Politakis P, Spanou E, Apostolou O, Pappas $S$ : Level of glycemic and lipid control among diabetic patients in Greek primary care. Eur J Gen Pract 2006, I2: 18I-182.

27. McFarlane S, Jacober S, Winer N, Kaur J, Castro J, Wui M, Gliwa A, Von Gizycki H, Sowers J: Control of cardiovascular risk factors in patients with diabetes and hypertension at urban academic medical centers. Diabetes Care 2002, 25:718-723.

28. Le Floch JP, Thervet F, Desriac I, Boyer JF, Simon D: Management of diabetic patients by general practitioners in France 1997: an epidemiological study. Diabetes Metab 2000, 26:43-49.

29. Belle Brown J, Harris SB, Webster-Bogaert S, Wetmore S, Faulds C, Stewart $M$ : The role of patient, physician and systemic factors in the management of type 2 diabetes mellitus. Fam Pract 2002, 19:344-349.

\section{Pre-publication history}

The pre-publication history for this paper can be accessed here:

http://www.biomedcentral.com/1472-6963/8/148/pre pub
Publish with Biomed Central and every scientist can read your work free of charge

"BioMed Central will be the most significant development for disseminating the results of biomedical research in our lifetime. "

Sir Paul Nurse, Cancer Research UK

Your research papers will be:

- available free of charge to the entire biomedical community

- peer reviewed and published immediately upon acceptance

- cited in PubMed and archived on PubMed Central

- yours - you keep the copyright
BioMedcentral 